\title{
Hyperglycaemia and pulmonary infection
}

\author{
Emma H. Baker*, David M. Wood, Amanda L. Brennan, Nicholas Clark, \\ Deborah L. Baines and Barbara J. Philips \\ Glucose and Pulmonary Infection Group, Cardiac and Vascular Sciences (Respiratory), \\ St George's, University of London, Cranmer Terrace, London SW17 ORE, UK
}

\begin{abstract}
Pathophysiological stress from acute illness causes metabolic disturbance, including altered hepatic glucose metabolism, increased peripheral insulin resistance and hyperglycaemia. Acute hyperglycaemia is associated with increased morbidity and mortality in patients in intensive care units and patients with acute respiratory disease. The present review will consider mechanisms underlying this association. In normal lungs the glucose concentration of airway secretions is approximately 10 -fold lower than that of plasma. Low airway glucose concentrations are maintained against a concentration gradient by active glucose transport. Airway glucose concentrations become elevated if normal homeostasis is disrupted by a rise in blood glucose concentrations or inflammation of the airway epithelium. Elevated airway glucose concentrations are associated with and precede increased isolation of respiratory pathogens, particularly methicillin-resistant Staphylococcus aureus, from bronchial aspirates of patients intubated on intensive care. Markers of elevated airway glucose are associated with similar patterns of respiratory infection in patients admitted with acute exacerbations of chronic obstructive pulmonary disease. Glucose at airway concentrations stimulates the growth of respiratory pathogens, over and above the effect of other nutrients. Elevated airway glucose concentrations may also worsen respiratory disease by promoting local inflammation. Hyperglycaemia may thus promote pulmonary infection, at least in part, by an effect on airway glucose concentrations. Therapeutic options, including systemic control of blood glucose and local manipulation of airway glucose homeostasis, will be considered.
\end{abstract}

Hyperglycaemia: Stress: Infection: Lung diseases: Insulin

\section{Stress, acute illness and hyperglycaemia}

Stress can be defined as 'a pathological process resulting from the reaction of the body to external forces and abnormal conditions that tends to disturb the organism's homeostasis' (National Library of Medicine, 2005). The present review will focus on the effect of the stress of acute illness on carbohydrate metabolism and the consequences of stress-induced hyperglycaemia, particularly in the lungs.

\section{Normal carbohydrate metabolism}

Blood glucose concentrations are normally maintained at about $4 \cdot 0-5 \cdot 5 \mathrm{mmol} / \mathrm{l}$, the optimal concentrations for brain function (Meisenberg \& Simmons, 1998). Blood glucose is supplied by dietary carbohydrates for a few hours after a meal, and subsequently maintained by hepatic glucose production (see Fig. 1(a)). The liver synthesises glucose both by the degradation of glycogen and by gluconeogenesis from non-carbohydrate precursors, including amino acids, lactic acid and glycerol. The relative contributions of hepatic glycogenolysis and gluconeogenesis to glucose production are hormonally regulated. Glucagon stimulates glycogenolysis in a rapid potent time-dependent manner that wanes as glycogen stores are depleted (Magnusson et al. 1995). Glucagon also has a slower less-potent stimulatory effect on gluconeogenesis that is limited by the availability of gluconeogenic substrates (Chhibber et al. 2000). Adrenaline stimulates glycogenolysis directly (Chu et al. 1996) and increases gluconeogenesis indirectly by enhancing peripheral substrate release (Chu et al. 1997). Cortisol stimulates gluconeogenesis through direct hepatic effects (Exton et al. 1976). These three hormones have an

\footnotetext{
Abbreviation: ICU, intensive care unit.

*Corresponding author: Dr Emma Baker, fax +44 208725 5955, email ebaker@sgul.ac.uk
} 
(a)

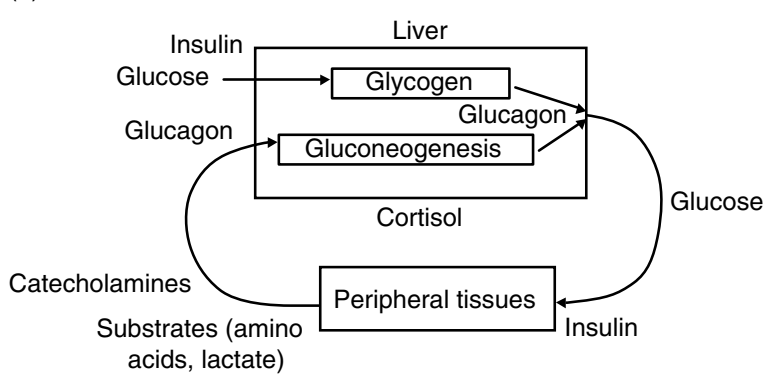

(b)

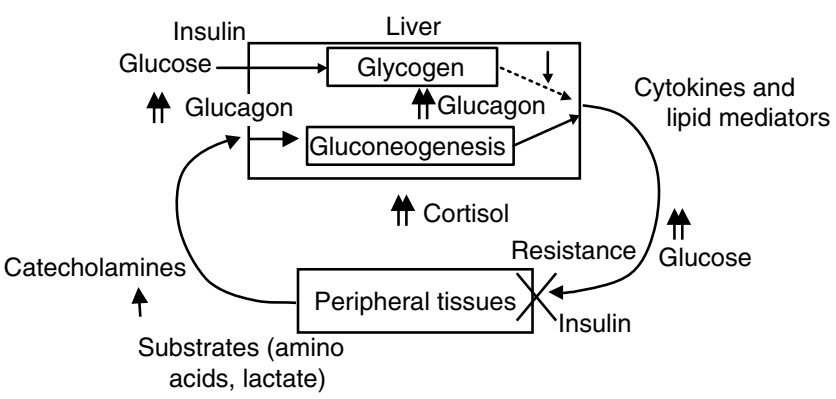

Fig. 1. Carbohydrate metabolism. (a) Normal carbohydrate metabolism. Blood glucose is maintained at approximately $4.0-5.5 \mathrm{mmol} / \mathrm{l}$. After a meal glucose is supplied by dietary carbohydrates, and increased insulin concentrations stimulate hepatic glucose storage as glycogen and peripheral glucose utilisation. At other times blood glucose is maintained by glycogenolysis and gluconeogenesis, regulated by glucagon. Gluconeogenesis requires substrates (amino acids, lactic acid, lipids) that are released from peripheral tissues in response to catecholamines. (b) Carbohydrate metabolism during acute stress. Increased concentrations of glucagon and cortisol stimulate gluconeogenesis, which is fuelled by increased peripheral substrate release that is driven by increased catecholamine concentrations. Inflammatory mediators, including cytokines, also induce reversible insulin resistance, resulting in failure to suppress hepatic glucose production and reduced glucose uptake in peripheral tissues. The net effect is hyperglycaemia. 4 , Increased concentrations; $\downarrow, \cdots$, reduced conversion of glycogen to glucose.

additive effect on glucose production (Lecavalier et al. 1990; Gustavson et al. 2003), particularly as adrenaline mobilises substrates for gluconeogenesis, which is enhanced by glucagon and cortisol. The actions of insulin oppose the effects of glucagon, catecholamines and cortisol. Insulin stimulates glucose-consuming pathways and suppresses glucose-producing pathways in the liver, as well as stimulating glucose uptake by peripheral tissues.

\section{Carbohydrate metabolism in acute illness}

In acute illness glucose production is increased and peripheral glucose clearance is decreased, resulting in elevated plasma glucose concentrations (see Fig. 1(b)). This response appears to be mediated by a combination of neurohumoral changes, cytokine production and the release of lipid mediators (McGuinness, 2005). Elevation of serum concentrations of glucagon, adrenaline and cortisol is observed in response to a variety of pathophysiological stresses (Rolih \& Ober, 1995), and infusion of these hormones in combination reproduces the marked hyperglycaemia, hyperinsulinaemia and accelerated glucose metabolism of acute illness (McGuinness et al. 1999). The contribution of individual hormones to stress hyperglycaemia has proved difficult to quantify, as in physiological models interventions to stimulate or block one hormone change the concentrations and effects of the other hormones. In the context of these limitations adrenaline has been shown to stimulate glucose production and inhibit glucose utilisation, in part by inhibiting pancreatic insulin secretion (McGuinness et al. 1999). Glucagon appears to divert glucose and gluconeogenic precursors from glycogen to glucose production, thus contributing to net hepatic glucose output (McGuinness et al. 1994a). Hepatic insulin resistance, with failure to suppress gluconeogenesis despite hyperglycaemia and increased circulating insulin levels, further contributes to the increased glucose production (Van den Berghe, 2004).

The induction of reversible insulin resistance by acute stress reduces peripheral glucose utilisation. Patients with sepsis show a reduction in glucose utilisation during hyperglycaemic clamping compared with controls, despite similar plasma insulin concentrations (White et al. 1987). Insulin resistance in acute stress has been attributed to inflammation and cytokine production. In mice the infusion of the proinflammatory cytokine IL- 6 both reduces insulinstimulated glucose uptake in skeletal muscle and blunts suppression of hepatic glucose production by insulin activity (Kim et al. 2004). Infusion of IL-10, an antiinflammatory cytokine, prevents IL-6-induced defects in insulin action and signalling activity (Kim et al. 2004). In rats the infusion of the proinflammatory cytokine TNF- $\alpha$ reduces insulin sensitivity within $24 \mathrm{~h}$ and induces insulin resistance over $4 \mathrm{~d}$ (Ruan et al. 2002). TNF- $\alpha$ neutralisation increases by $68 \%$ the rate of glucose infusion required to maintain euglycaemia in rats during hyperinsulinaemic euglycaemic clamp studies, stimulating glucose uptake by skeletal muscle (Borst et al. 2004). Furthermore, TNF$\alpha$-deficient knock-out mice with diet-induced obesity respond to an exogenous dose of insulin or glucose much more efficiently than wild-type mice expressing TNF- $\alpha$ (Hotamisligil, 1999). The mechanism of cytokine-induced insulin resistance is not fully understood, but may be the result of a direct effect on insulin receptor signalling. Increased cytokine concentrations stimulate the generation of 'suppressor of cytokine-signalling' proteins, which act as negative-feedback inhibitors of cytokine signal transduction (Mao et al. 1999). 'Suppressor of cytokinesignalling' proteins have been shown to inhibit insulin receptor tyrosine phosphorylation and downstream signal transduction (Senn et al. 2003) and to degrade insulin receptor substrate (Rui et al. 2002).

\section{Definition of hyperglycaemia}

As the understanding of the pathophysiological consequences of hyperglycaemia has increased, the definition of hyperglycaemia has changed. The diagnosis of diabetes mellitus requires either that fasting blood glucose should be $\geq 7.0 \mathrm{mmol} / \mathrm{l}$ on two or more occasions or that random blood glucose should be $\geq 11.0 \mathrm{mmol} / 1$ on one occasion, 
combined with symptoms of diabetes (Expert Committee on the Diagnosis and Classification of Diabetes Mellitus, 2003). A number of studies investigating the effect of glucose in acute illness have therefore defined acute hyperglycaemia as blood glucose of $\geq 11 \mathrm{mmol} / 1$ (Malmberg et al. 1995; Umpierrez et al. 2002; McAlister et al. 2005). However, evidence of adverse effects of blood glucose above physiological concentrations $(>6.0 \mathrm{mmol} / \mathrm{l})$ but below diabetic concentrations $(<11.0 \mathrm{mmol} / \mathrm{l})$ in acute illness has led investigators to consider any blood glucose concentration above physiological concentrations to be hyperglycaemia in acute stress (Capes et al. 2001; Van den Berghe et al. 2001).

\section{Hyperglycaemia and poor outcomes from acute illness}

Hyperglycaemia, by either definition, is extremely common in acute illness. It has been reported (Umpierrez et al. 2002) that $38 \%$ of adults admitted acutely to general hospital wards were found to have hyperglycaemia, defined as blood glucose at admission or fasting blood glucose of $\geq 7 \mathrm{mmol} / 1$ or two random blood glucose measurements of $\geq 11 \cdot 1 \mathrm{mmol} / \mathrm{l}$. In one-third of the group with elevated blood glucose the hyperglycaemia had been newly diagnosed, and in-hospital mortality was found to be higher in this group $(16 \%)$ than in those with established diabetes mellitus $(3 \%)$ or normal blood glucose $(1.7 \%$; Umpierrez et al. 2002). Furthermore, hospital stay was reported to be longer and intensive care unit (ICU) admission more frequent in those patients with newly-diagnosed hyperglycaemia. Other studies have shown that hyperglycaemia (various definitions) is also associated with adverse outcomes from acute myocardial infarction (Capes et al. 2000), ischaemic or haemorrhagic stroke (Capes et al. 2001), surgery (Hill Golden et al. 1999) and trauma (Yendarumi et al. 2003). Blood glucose control with insulin improves outcomes from myocardial infarction (Malmberg et al. 1995) and ICU admission following cardiothoracic surgery (Van den Berghe et al. 2001). Regression analysis has found that control of glucose levels, rather than insulin dose, is responsible for the clinical benefits observed (Finney et al. 2003; Van den Berghe et al. 2003). These findings imply that elevated glucose concentrations have a direct detrimental effect on outcomes.

\section{Potential mechanisms}

Hyperglycaemia could have adverse effects in acute illness through cellular glucose overload and oxidative stress. In acute illness cytokines, hormones and hypoxia up regulate expression and membrane localisation of glucose transporters in many cell types (Van den Berghe, 2004). Cellular glucose overload results in increased glucose metabolism, in turn increasing superoxide and peroxynitrite production, which may impair mitochondrial activity (Van den Berghe, 2004). In support of this finding, ultrastructural abnormalities have been observed in hepatic mitochondria obtained at liver biopsy from patients in the ICU with hyperglycaemia, whereas virtually no mitochondrial abnormalities are detected in patients in whom normoglycaemia is maintained therapeutically (Vanhorebeek et al. 2005). The mitochondrial toxicity of glucose in diverse cells could account for the broad spectrum of organ and tissue dysfunction associated with hyperglycaemia in acute illness (Van den Berghe et al. 2001).

Acute hyperglycaemia is associated with increased risk of infection (Khaodhiar et al. 1999; Vriesendorp et al. 2004), and insulin therapy to normalise blood glucose reduces septicaemia by $46 \%$ and the need for prolonged antibiotic therapy by $35 \%$ compared with conventional therapy (Van den Berghe et al. 2001). Systemic immune defects in patients with diabetes include decreased neutrophil and macrophage chemotaxis, phagocytosis and killing, and impairment in complement and cytokine responses to infection (Geerlings \& Hoepelman, 1999). Similar systemic immune dysfunction could contribute to increased infection risk in acute hyperglycaemia. Additionally, elevated glucose concentrations could have local effects on host immunity or bacterial growth, which could promote infection.

\section{Hyperglycaemia and pulmonary infection}

Two recent studies have shown that acute hyperglycaemia is associated with poor outcomes from hospital admission for pulmonary infection. Patients with hospital-acquired pneumonia who have a blood glucose concentration of $>11 \mathrm{mmol} / \mathrm{l}$ have an increased risk of death and in-hospital complications compared with those with a blood glucose concentration of $\leq 11 \mathrm{mmol} / \mathrm{l}$ (McAlister et al. 2005). An increase in blood glucose concentration of $1 \mathrm{mmol} / \mathrm{l}$ is associated with a $3 \%$ increase in the risk of in-hospital complications (McAlister et al. 2005). It has been found that $50 \%$ of patients admitted with acute exacerbations of chronic obstructive pulmonary disease have a blood glucose concentration of $\geq 7.0 \mathrm{mmol} / 1$ (Baker et al. 2006). Relative risk of death or prolonged hospital stay is greatest in those patients with the highest blood glucose concentrations (highest blood glucose quartile $v$. lowest blood glucose quartile; relative risk 1.97 (95\% CI 1.33, 2.92), $P<0.0001)$ and increases by $14 \%$ with each $1 \mathrm{mmol} / \mathrm{l}$ increase in blood glucose concentration (Baker et al. 2006). In patients with acute exacerbations of chronic obstructive pulmonary disease multiple pathogens and Staphylococcus aureus are isolated from sputum more frequently as blood glucose concentrations increase, raising the question as to whether hyperglycaemia could directly influence airway infection.

\section{Glucose concentrations in airway surface liquid}

The air spaces in the lung are lined with a thin layer of fluid (airway surface liquid). The volume and composition of airway surface liquid are carefully regulated and are critical for lung defence. Animal studies have shown that the glucose concentration of airway surface liquid is 3-20fold lower than that of plasma (Barker et al. 1989; Icard \& Saumon, 1999). Glucose has not been detected in nasal secretions from healthy human volunteers using modified 
glucose oxidase sticks (lower limit of detection approximately $0.5 \mathrm{mmol} / \mathrm{l}$; Philips et al. 2003). Liquid from normal human lower airways, sampled non-invasively by exhaled breath condensate collection, contains $0 \cdot 4($ SD $0 \cdot 2)$ mmol glucose/l (Clark et al. 2004).

Hyperglycaemia. Airway glucose concentrations become elevated when blood glucose is raised. Glucose concentrations are $1-9 \mathrm{mmol} / \mathrm{l}$ in nasal secretions from patients with treated diabetes mellitus and $1-11 \mathrm{mmol} / \mathrm{l}$ in bronchial aspirates from patients in the ICU with stress hyperglycaemia (Philips et al. 2003). The relationship between blood and airway glucose concentrations has been clarified in healthy volunteers using a modified hyperglycaemic clamp technique (Wood et al. 2004b). Glucose is not detected in nasal secretions at baseline (blood glucose $5 \mathrm{mmol} / \mathrm{l}$ ), but becomes detectable in nasal secretions within $10 \mathrm{~min}$ of blood glucose elevation to $12 \mathrm{mmol} / \mathrm{l}$ (Wood et al. 2004b). Nasal glucose reaches a maximum concentration of $4.8(\mathrm{SD} 2 \cdot 2) \mathrm{mmol} / \mathrm{l}$ then falls to control values when blood glucose is allowed to return to baseline. A blood glucose 'threshold' of $6.7-9.7 \mathrm{mmol} / \mathrm{l}$ has been identified, above which glucose becomes detectable in nasal secretions (Wood et al. 2004b). Liquid from the lower airways of patients with diabetes (sampled as exhaled breath condensate) contains $1.2(\mathrm{SD} 0 \cdot 7) \mathrm{mmol} / \mathrm{l}$ glucose as compared with $0 \cdot 4(\mathrm{SD} 0 \cdot 2) \mathrm{mmol} / \mathrm{l}$ glucose in airway surface liquid from healthy volunteers $(P<0 \cdot 0001$; Clark et al. 2004). Glucose concentrations in lower-airway secretions also increase in response to experimental hyperglycaemia (Clark et al. 2006).

Inflammation. Airway glucose concentrations are elevated when the airway epithelium is inflamed. Glucose is detected at $1-2 \mathrm{~mm}$ in nasal secretions from healthy volunteers during acute viral rhinitis and disappears with resolution of the symptoms (Philips et al. 2003). Glucose concentrations are elevated in liquid from the lower airways of patients with cystic fibrosis who have airway inflammation and normal glucose tolerance (Brennan et al. 2006). The effects of inflammation and hyperglycaemia appear to be additive, as glucose concentrations are elevated further in liquid from the lower airways of patients with cystic fibrosis who also have diabetes mellitus (Brennan et al. 2006).

Airway glucose homeostasis. The observation that glucose concentrations are 10-fold lower in human airways than in plasma implies that glucose is actively removed from the airway lumen against the glucose concentration gradient. Animal studies have indicated that glucose is removed from the airway lumen by $\mathrm{Na}^{+}$-dependent glucose transporters in the apical membrane of airway epithelial cells (Barker et al. 1989; Saumon et al. 1996). Glucose transport from the lumen by $\mathrm{Na}^{+}$-dependent glucose transporters is driven by a $\mathrm{Na}^{+}$gradient that is generated by $\mathrm{Na}^{+}-\mathrm{K}^{+}$ATPase pumps in the basolateral membrane of epithelial cells (Fig. 2(a)). Animal airway epithelial cells also express the facilitative GLUT (Devaskar \& de Mello, 1996), although the polarity of expression and function of the GLUT in airway epithelium has not been fully elucidated. It has been shown that $\mathrm{Na}^{+}$-dependent glucose transporter-1 and GLUT2 are expressed at mRNA and protein level in human nasal epithelium and in (a)

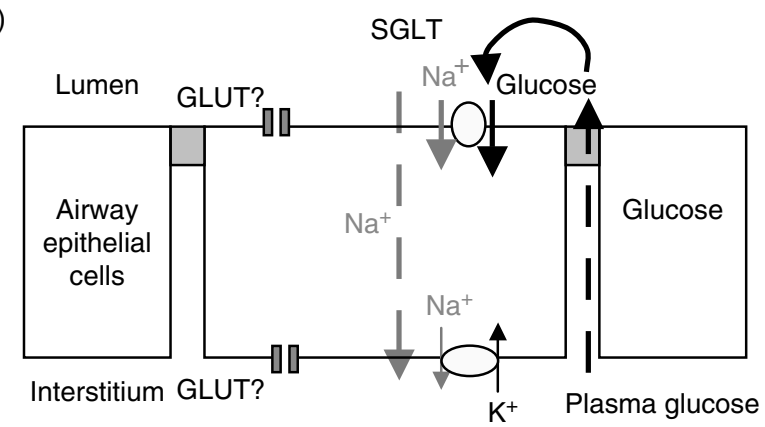

(b)
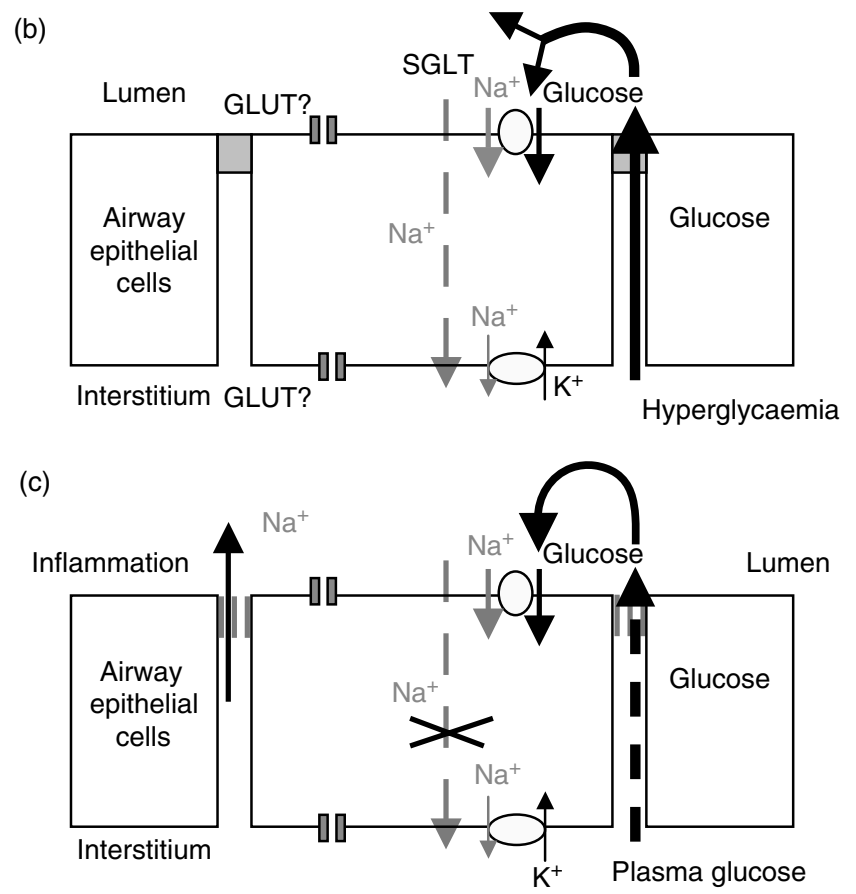

Fig. 2. Proposed model of airway glucose homeostasis. (a) Airway glucose homeostasis: the airway epithelial cells are interspersed with tight junctions, forming a resistant epithelium. Glucose moves down its concentration gradient from plasma to lumen across the epithelium, probably by paracellular diffusion. Glucose is removed from the airway lumen by sodium ion-dependent glucose transporters (SGLT) present in apical membranes of epithelial cells, maintaining low lumen glucose concentrations. SGLT transport is driven by a sodium ion gradient generated by $\mathrm{Na}^{+}-\mathrm{K}^{+}$ATPase pumps in the basolateral membrane. Facilitative GLUT are also expressed by airway epithelial cells, although their polarity of expression and function is not known. (b) Hyperglycaemia: when blood glucose is raised the concentration gradient for glucose from plasma to the lumen increases and more glucose diffuses into the airway lumen. At blood glucose concentrations of $>6.7-9.7 \mathrm{~mm}$ (Wood et al. $2004 b)$ lumen glucose concentrations exceed the capacity of glucose transport and airway glucose concentrations rise. (c) Inflammation: the permeability of the airway epithelium is increased, possibly as a result of structural changes in tight junctions, thus dissipating the transepithelial sodium ion gradient, reducing glucose absorption by SGLT and elevating airway glucose concentrations.

immortalised cell lines from the proximal (H441) and distal (A549) airway (Wood et al. 2004a), implying that glucose homeostasis is similar in human airways. In support of this notion $\mathrm{Na}^{+}$-dependent glucose transporter-1 
mRNA (Ishikawa et al. 2001), but not protein (Devaskar \& de Mello, 1996), and GLUT2 protein (Ito et al. 1998) expression have been demonstrated in non-cancerous regions of human lung obtained at autopsy from patients with primary lung carcinomas. A proposed model of glucose homeostasis in human airways is shown in Fig. 2(a). In this model the effect of hyperglycaemia on airway glucose concentrations is explained by increased movement of glucose into the airway lumen, which overwhelms transport processes that remove glucose from airway secretions (Fig. 2(b)). Inflammation could elevate airway glucose concentrations by increasing airway permeability, which would both increase glucose movement into the lumen and reduce the $\mathrm{Na}^{+}$gradient driving glucose transport out of the lumen (Fig. 2(c)).

\section{Glucose and infection in the airways}

\section{Association studies}

Glucose in airway secretions is associated with the acquisition of respiratory infection in patients in the ICU who are intubated (Philips et al. 2005). Patients with glucose present in bronchial aspirates are more likely to have pathogenic bacteria detected in sputum (relative risk $2 \cdot 4$ (95\% CI 1.5, 3.8)), particularly methicillin-resistant S. aureus (relative risk $2 \cdot 1(95 \%$ CI $1 \cdot 2,3 \cdot 8)$ ), than those without bronchial glucose. Furthermore, glucose in airway secretions on admission to the ICU are associated with subsequent acquisition of methicillin-resistant S. aureus (relative risk $1 \cdot 8(95 \%$ CI $1 \cdot 1,3 \cdot 6)$ ), implying that glucose precedes infection. It has also been found that multiple respiratory pathogens and methicillin-resistant $S$. aureus are isolated more frequently from sputum of patients admitted with acute exacerbations of chronic obstructive pulmonary disease and hyperglycaemia, although direct measurements of airway glucose were not made (Baker et al. 2006).

\section{Glucose and bacterial growth}

Glucose in airway secretions could promote respiratory infection through direct effects on bacterial growth. Bacteria utilise saccharides both as substrates for catabolic reactions to provide energy for growth and as C for the biosynthesis of new cellular material (Mortlock, 1998). S. aureus and Pseudomonas aeruginosa, which are important causes of nosocomial (hospital-acquired) respiratory infection in patients with stress-induced hyperglycaemia, both possess transporters that allow cellular uptake of D-glucose and are able to metabolise D-glucose (Reizer et al. 1988; Adewoye \& Worobec, 2000). In laboratory culture glucose at concentrations found in airway secretions $(0 \cdot 5-10 \mathrm{mmol} / \mathrm{l})$ promotes a dose-dependent increase in the growth of $S$. aureus (Brennan et al. 2004) and $0.56 \mathrm{mmol}$ glucose/l supports growth of $P$. aeruginosa without other nutrients (Chance \& Mawhinney, 2000).

\section{Glucose and bacterial pathogenicity}

Changes in the environmental nutrient composition can alter bacterial gene expression, leading to changes in virulence. Laboratory culture of mucoid strains of $P$. aeruginosa in high glucose concentrations (approximately $50 \mathrm{mmol} / \mathrm{l}$ ) induces $\operatorname{alg} D$ transcription, increasing the production of alginate, a viscous exopolysaccharide that causes pulmonary deterioration in cystic fibrosis (Ma et al. 1997). Glucose at pathophysiological concentrations stimulates both $P$. aeruginosa $(11.1 \mathrm{mmol} / \mathrm{l})$ and $S$. aureus to form biofilms, adherent slime-encased bacterial communities that allow bacterial survival and antibiotic resistance (Kievit et al. 2001).

\section{Glucose and airway inflammation}

Glucose in airway secretions could moderate the inflammatory response to infection. Serum concentrations of proinflammatory cytokines, including IL-6, soluble IL-6 receptors (Esposito et al. 2002; Muller et al. 2002; Yu et al. 2003) and TNF- $\alpha$ (Esposito et al. 2002; Yu et al. 2003), are elevated in patients with impaired glucose tolerance compared with controls with normal glucose tolerance. Experimental elevation of blood glucose in patients with normal glucose tolerance when they are clinically stable (Esposito et al. 2002) or during sepsis (Yu et al. 2003) stimulates acute increases in plasma IL-6 and TNF- $\alpha$. Plasma IL- 8 increases after an oral glucose load in patients with impaired glucose tolerance (Straczkowski et al. 2003). The stimulatory effect of glucose on IL-6 and TNF- $\alpha$ production is ameliorated by glutathione infusion, implying that an oxidative mechanism is involved (Esposito et al. 2002). In addition, advanced glycation end products, formed by a non-enzymic reaction of glucose with protein $\mathrm{NH}_{2}$ groups, up regulates IL- 8 and TNF- $\alpha$ production by human monocyte-derived macrophages (Pertynska-Marczewska et al. 2004). There is no published information on the effects of glucose on cytokine production in the airway. However, respiratory pathogens increase airway epithelial expression of proinflammatory cytokines, including IL-6, IL-8 and TNF- $\alpha$ (Khair et al. 1994), which could be further up regulated by elevated airway glucose, increasing inflammation and disease severity.

\section{Nutritional and therapeutic implications}

Nutritional support and stress hyperglycaemia

In folklore one version of the advice relating to the treatment of infections suggests 'If you feed a cold, you'll have to starve a fever later'. Recent research into altered response to nutritional support during acute stress perhaps provides new validity for this old saying. In individuals receiving enteral and parenteral nutritional support without acute stress glucose is handled predominantly by the liver (McGuinness, 2005). Physiological studies in dogs have demonstrated that the liver takes up approximately $50 \%$ of the glucose delivered as chronic total parenteral or enteral nutrition (McGuinness et al. 1998; Chen et al. 2000). Glucose that is taken up by the liver is predominantly converted to lactate, a substrate that can be taken up by peripheral tissues independently of insulin, thus ensuring effective glucose disposal (McGuinness et al. 1998). In 
human subjects studies of liver metabolism are limited by a lack of access to the hepatic and portal veins. However, during prolonged moderate experimental hyperglycaemiahyperinsulinaemia $40 \%$ of the infused glucose is taken up by the splanchnic region, implying a similar role for the liver in glucose disposal in human subjects during nutritional support (Sidossis et al. 1999).

In acute stress the adaptation of the liver to nutritional support is markedly impaired. Net hepatic glucose uptake and lactate output are markedly decreased (McGuinness et al. 1998). Additionally, glycogen deposition is reduced and suppression of hepatic glucose production is impaired (McGuinness et al. 1995). The hormonal changes in acute stress contribute to the abnormal response to nutritional support. Elevated glucagon concentrations impair net hepatic glucose uptake (McGuinness et al. 1994b). Additionally, glucagon stimulates glucose production by gluconeogenesis (McGuinness et al. 1994a), which may increase during parenteral or enteral nutrition because of increased supplies of precursor amino acids and lipids. 'Feeding', i.e. nutritional support, thus exacerbates the extent of hyperglycaemia seen during acute stress (Patino et al. 1999). This augmented hyperglycaemia may further increase the risk of secondary infection and up regulate the inflammatory response, thus inducing a 'fever later'. This process may be particularly relevant in 'colds', as airway epithelial permeability is increased during viral rhinitis (Philips et al. 2003). Inflammation combined with hyperglycaemia results in additional elevation of airway glucose concentrations (Brennan et al. 2006), in turn increasing the risk of acquiring bacterial respiratory infection (Philips et al. 2005). Patino et al. (1999) have demonstrated the effectiveness of 'starving the fever later', as patients receiving hypoenergetic-hyperproteic total parenteral nutrition regimens on a surgical ICU have a more physiological clinical course with less metabolic stress than those receiving high-energy loads.

\section{Insulin}

Despite increased insulin resistance in acute stress (White et al. 1987), insulin therapy is effective in the normalisation of blood glucose and reduction of adverse outcomes in acute illness. In a prospective study of 1548 patients admitted to a cardiothoracic surgical ICU (Van den Berghe et al. 2001) intensive blood glucose control with insulin (blood glucose $4 \cdot 4-6 \cdot 1 \mathrm{~mm}$ ) has been shown to reduce intensive care mortality by $43 \%$, in-hospital mortality by $34 \%$, septicaemia by $46 \%$ and the need for prolonged antibiotic therapy by $35 \%$ compared with conventional therapy (blood glucose 10-11.1 mm). Similar results have been seen in a more heterogeneous population of criticallyill adults on a general ICU (Krinsley \& Grissler, 2005), with blood glucose control to $<7 \cdot 2 \mathrm{~mm}$ reducing in-hospital mortality by $29 \%$ and ICU length of stay by $11 \%$. The beneficial effects of intensive insulin therapy are related to metabolic control, as reflected by normoglycaemia, rather than the infused insulin dose (Van den Berghe et al. 2003). However, insulin may also have benefits that are independent of its effects on blood glucose. In the surgical ICU study (Van den Berghe, 2004) intensive insulin therapy was shown to be associated with an improvement in dyslipidaemia, higher skeletal muscle protein content, reduced inflammation (as indicated by lowered C-reactive protein and mannose-binding lectin levels) and down-regulation of the adhesion molecules intercellular adhesion molecule-I and E-selectin. Insulin may also have direct effects on the airway, which may be of importance in the prevention or treatment of pulmonary infection.

\section{Insulin in the airway}

In patients in the ICU systemic insulin therapy is associated with the clearance of glucose from bronchial aspirates (BJ Philips, personal communication). This finding may simply be attributable to an effect of insulin on blood glucose. However, physiological insulin concentrations stimulate the uptake of 2-deoxyglucose by rat alveolar type II epithelial cells (Sugahara et al. 1984), implying a possible role for insulin in the up-regulation of pulmonary glucose clearance. Insulin could also have direct effects on infection and inflammation. Insulin therapy reduces pulmonary influenza A viral titres in diabetic mice (Reading et al. 1998) and reduces sputum examinations positive for Haemophilus influenzae and Streptococcus pneumoniae in patients with cystic fibrosis-related diabetes (Lanng et al. 1994). There have been no studies of the effect of insulin on airway inflammation. However, systemic insulin has anti-inflammatory effects, mediated through the suppression of major proinflammatory transcription factors (Dandona et al. 2005), and potentially could have antiinflammatory effects in the airway. Imminent licensing of inhaled insulin preparations will provide the opportunity for further exploration of the direct effects of insulin on glucose clearance, infection and inflammation in the airway.

\section{Conclusion}

Stress hyperglycaemia is common in acute illness and is associated with increased risk of poor outcome from respiratory infection. It has been shown that the glucose concentration in the airway increases as blood glucose rises and that elevated airway glucose concentrations are associated with the acquisition of respiratory infection, at least in intensive care. Further studies are required to determine whether elevated glucose concentrations are truly detrimental in airway secretions and to establish the place of therapies that lower airway glucose concentrations in the treatment of airway infection and inflammation.

\section{References}

Adewoye LO \& Worobec EA (2000) Identification and characterisation of the gltK gene encoding a membrane-associated glucose transport protein of Pseudomonas aeruginosa. Gene 253, 323-330.

Baker EH, Janaway CH, Philips BJ, Brennan AL, Baines DL, Wood DM \& Jones PW (2006) Hyperglycaemia is associated with poor outcomes in people admitted to hospital with acute exacerbations of chronic obstructive pulmonary disease. Thorax 61, 284-289. 
Barker PM, Boyd CA, Ramsden CA, Strang LB \& Walters DV (1989) Pulmonary glucose transport in the fetal sheep. Journal of Physiology 409, 15-27.

Borst SE, Lee Y, Conover CF, Shek EW \& Bagby GJ (2004) Neutralization of tumor necrosis factor-alpha reverses insulin resistance in skeletal muscle but not adipose tissue. American Journal of Physiology 287, E934-E938.

Brennan AL, Gyi KM, Clark N, Fisher DA, Wood DM, Baines DL, Philips BJ, Geddes DM, Hodson ME \& Baker EH (2006) Detection of elevated glucose concentrations in lower airway secretions from people with cystic fibrosis. Thorax 60 (sII), ii93.

Brennan AL, Johnson J, Holliman R, Philips BJ \& Baker EH (2004) Glucose at concentrations found in airway secretions increases the growth of Staphylococcus aureus. American Journal of Respiratory and Critical Care Medicine 169, A371.

Capes SE, Hunt D, Malmberg K \& Gerstein HC (2000) Stress hyperglycaemia and increased risk of death after myocardial infarction in patients with and without diabetes: a systematic overview. Lancet 355, 773-778.

Capes SE, Hunt D, Malmberg K, Pathak P \& Gerstein HC (2001) Stress hyperglycemia and prognosis of stroke in nondiabetic and diabetic patients: a systematic overview. Stroke 32, 24262432.

Chance DL \& Mawhinney TP (2000) Carbohydrate sulfation effects on growth of Pseudomonas aeruginosa. Microbiology 146, 1717-1725.

Chen SS, Donmoyer C, Zhang Y, Hande SA, Lacy DB \& McGuinness OP (2000) Impact of enteral and parenteral nutrition on hepatic and muscle glucose metabolism. Journal of Parenteral and Enteral Nutrition 24, 255-260.

Chhibber VL, Soriano C \& Tayek JA (2000) Effects of low-dose and high-dose glucagon on glucose production and gluconeogenesis in humans. Metabolism 48, 39-46.

Chu CA, Sindelar DK, Neal DW, Allen EJ, Donahue EP \& Cherrington AD (1997) Comparison of the direct and indirect effects of epinephrine on hepatic glucose production. Journal of Clinical Investigation 99, 1044-1056.

Chu CA, Sindelar DK, Neal DW \& Cherrington AD (1996) Direct effects of catecholamines on hepatic glucose production in conscious dog are due to glycogenolysis. American Journal of Physiology 271, E127-E137.

Clark N, Fisher DA, Wood DM, Brennan AL, Philips BJ, Baines DL, Grimble G \& Baker EH (2004) Developing methods for determining dilution factor and measuring low glucose concentrations in exhaled breath condensate. Thorax 59, Suppl. II, ii46.

Clark N, Wood DM, Fisher DA, Ruffles T, Brennan AL, Philips BJ, Baines DL \& Baker EH (2006) Effect of changes in blood glucose concentration on glucose concentrations of lower airway secretions sampled by exhaled breath condensate. Thorax 60 (sII), ii87.

Dandona P, Mohanty P, Chaudhuri A, Garg R \& Aljada A (2005) Insulin infusion in acute illness. Journal of Clinical Investigation 115, 2069-2072.

Devaskar SU \& de Mello DE (1996) Cell-specific localization of glucose transporter proteins in mammalian lung. Journal of Clinical Endocrinology and Metabolism 81, 4373-4378.

Esposito K, Nappo F, Marfella R, Giugliano G, Giugliano F, Ciotola M, Quagliaro L, Ceriello A \& Guigliano D (2002) Inflammatory cytokine concentrations are acutely increased by hyperglycaemia in humans: role of oxidative stress. Circulation 106, 2067-2072.

Expert Committee on the Diagnosis and Classification of Diabetes Mellitus (2003) Report of the Expert Committee on the Diagnosis and Classification of Diabetes Mellitus. Diabetes Care 25, Suppl., S5-S20.
Exton JH, Miller TB, Harper SC \& Park CR (1976) Carbohydrate metabolism in perfused livers of adrenalectomized and steroidreplaced rats. American Journal of Physiology 230, 163-170.

Finney SJ, Zekveld C, Elia A \& Evans TW (2003) Glucose control and mortality in critically ill patients. Journal of the American Medical Association 290, 2041-2047.

Geerlings SE \& Hoepelman AI (1999) Immune dysfunction in patients with diabetes mellitus (DM). FEMS Immunology and Medical Microbiology 26, 259-265.

Gustavson SM, Chu CA, Nishizawa M, Farmer B, Neal D, Yang Y, Donahue EP, Flakoll P \& Cherrington AD (2003) Interaction of glucagon and epinephrine in the control of hepatic glucose production in the conscious dog. American Journal of Physiology 284, E695-E707.

Hill Golden S, Peart-Vigilance C, Kao WH \& Brancati FL (1999) Perioperative glycemic control and the risk of infectious complications in a cohort of adults with diabetes. Diabetes Care 22, 1408-1414.

Hotamisligil GS (1999) Mechanisms of TNF-alpha-induced insulin resistance. Experimental and Clinical Endocrinology \& Diabetes 107, 119-125.

Icard P \& Saumon G (1999) Alveolar sodium and liquid transport in mice. American Journal of Physiology 277, L1232-L1238.

Ishikawa N, Oguri T, Isobe T, Fujitaka K \& Kohno N (2001) SGLT gene expression in primary lung cancers and their metastatic lesions. Japanese Journal of Cancer Research 92 , 874-879.

Ito T, Noguchi Y, Satoh S, Hayashi H, Inayama Y \& Kitamura H (1998) Expression of facilitative glucose transporter isoforms in lung carcinomas: its relation to histologic type, differentiation grade, and tumor stage. Modern Pathology 11, 437-443.

Khair OA, Devalia JL, Abdelaziz MM, Sapsford RJ, Tarraf H \& Davies RJ (1994) Effect of haemophilus influenzae endotoxin on the synthesis of IL-6, IL-8, TNF-alpha and expression of ICAM-1 in cultured human bronchial epithelial cells. The European Respiration Journal 7, 2109-2116.

Khaodhiar L, McCowen K \& Bistrian B (1999) Perioperative hyperglycemia, infection or risk? Current Opinion in Clinical Nutrition and Metabolic Care 2, 79-82.

Kievit TR, Gillis R, Marx S, Brown C \& Iglewski BH (2001) Quorum-sensing genes in Pseudomonas aeruginosa biofilms: their role and expression patterns. Applied and Environmental Microbiology 67, 1865-1873.

Kim HJ, Higashimori T, Park SY, Choi H, Dong J, Kim YJ, Noh HL, Cho YR, Cline G, Kim YB \& Kim JK (2004) Differential effects of interleukin-6 and -10 on skeletal muscle and liver insulin action in vivo. Diabetes 53, 1060-1067.

Krinsley J \& Grissler B (2005) Intensive glycemic management in critically ill patients. Joint Commission Journal on Quality and Patient Safety 31, 308-312.

Lanng S, Thorsteinsson B, Nerup J \& Koch C (1994) Diabetes mellitus in cystic fibrosis: effect of insulin on lung function and infections. Acta Paediatrica 83, 849-853.

Lecavalier L, Bolli G \& Gerich J (1990) Glucagon-cortisol interactions on glucose turnover and lactate gluconeogenesis in normal humans. American Journal of Physiology 258, E569E575.

McAlister FA, Majumdar SR, Blitz S, Rowe BH, Romney J \& Marrie TJ (2005) The relation between hyperglycemia and outcomes in 2,471 patients admitted to the hospital with community-acquired pneumonia. Diabetes Care 28, 810-815.

McGuinness OP (2005) Defective glucose homeostasis during infection. Annual Review of Nutrition 25, 9-35.

McGuinness OP, Burgin K, Moran C, Bracy D \& Cherrington $\mathrm{AD}$ (1994a) Role of glucagon in the metabolic response to stress hormone infusion in the conscious dog. American Journal of Physiology 266, E438-E447. 
McGuinness OP, Donmoyer C, Ejiofor J, McElligott S \& Lacy DB (1998) Hepatic and muscle glucose metabolism during total parenteral nutrition: impact of infection. American Journal of Physiology 275, E763-E769.

McGuinness OP, Jacobs J, Moran C \& Lacey DB (1995) Impact of infection on hepatic disposal of a peripheral glucose infusion in the conscious dog. American Journal of Physiology 269, E199-E207.

McGuinness OP, Murrell S, Moran C, Bracy D \& Cherrington AD (1994b) The effect of acute glucagon removal on the metabolic response to stress hormone infusion in the conscious dog. Metabolism 43, 1310-1317.

McGuinness OP, Snowden RT, Moran C, Neal DW, Fujiwara T $\&$ Cherrington AD (1999) Impact of acute epinephrine removal on hepatic glucose metabolism during stress hormone infusion. Metabolism 48, 910-914.

Ma J-F, Phibbs PV \& Hassett DJ (1997) Glucose stimulates alginate production and algD transcription in Pseudomonas aeruginosa. FEMS Microbiology Letters 148, 217-221.

Magnusson I, Rothman DL, Gerard DP, Katz LD \& Shulman GI (1995) Contribution of hepatic glycogenolysis to glucose production in humans in response to a physiological increase in plasma glucagon concentration. Diabetes 44, 185-189.

Malmberg K, Ryden L, Efendic S, Herlitz J, Nicol P, Waldenstrom A, Wedel H \& Welin L (1995) Randomized trial of insulin-glucose infusion followed by subcutaneous insulin treatment in diabetic patients with acute myocardial infarction (DIGAMI Study): effects on mortality at 1 year. Journal of the American College of Cardiology 26, 57-65.

Mao Y, Ling PR, Fitzgibbons TP, McCowen KC, Frick GP, Bistrian BR \& Smith RJ (1999) Endotoxin-induced inhibition of growth hormone receptor signaling in rat liver in vivo. Endocrinology 140, 5505-5515.

Meisenberg G \& Simmons WH (editors) (1998) Principles of Medical Biochemistry, 1st ed., p. 333. St Louis, MO: Mosby Inc.

Mortlock RP (1998) Bacterial growth and metabolism. In Microbiology and Microbial Infections, vol. 2, 9th ed., pp. 85-124 [L Collier, A Balows and M Sussman, editors]. London: Arnold.

Muller S, Martin S, Koenig W, Hanifi-Moghaddam P, Rathmann W, Haastert B, Giani G, Illig T, Thorand B \& Kolb H (2002) Impaired glucose tolerance is associated with increased serum concentrations of interleukin 6 and co-regulated acute-phase proteins but not TNF-alpha or its receptors. Diabetologica $\mathbf{4 5}$, 805-812.

National Library of Medicine (2005) MeSH database. http:// www.ncbi.nlm.nih.gov/entrez/query.fcgi?CMD=search\&DB= mesh

Patino JF, de Pimiento SE, Vergara A, Savino P, Rodriguez M \& Escallon J (1999) Hypocaloric support in the critically ill. World Journal of Surgery 23, 553-559.

Pertynska-Marczewska M, Kiriakidis S, Wait R, Beech J, Feldmann M \& Paleolog EM (2004) Advanced glycation end products upregulate angiogenic and proinflammatory cytokine production in human monocyte/macrophages. Cytokine 28, 35-47.

Philips BJ, Meguer J-X, Redman J \& Baker EH (2003) Factors determining the appearance of glucose in upper and lower respiratory tract secretions. Intensive Care Medicine 29, 2204-2210.

Philips BJ, Redman J, Brennan AL, Wood DM, Holliman R, Baines DL \& Baker EH (2005) Glucose in bronchial aspirates increases the risk of respiratory MRSA in intubated patients. Thorax 60, 761-764.

Reading PC, Allison J, Crouch EC \& Anders EM (1998) Increased susceptibility of diabetic mice to influenza virus infection: compromise of collectin-mediated host defence of the lung by glucose. Journal of Virology 72, 6884-6887.

Reizer J, Saier MH Jr, Deutscher J, Grenier F, Thompson J \& Hengstenberg W (1988) The phosphoenolpyruvate: sugar phosphotransferase system in gram-positive bacteria: properties, mechanism, and regulation. Critical Reviews in Microbiology 15, 297-338.

Rolih CA \& Ober KP (1995) The endocrine response to critical illness. Medical Clinics of North America 79, 211224

Ruan H, Miles PD, Ladd CM, Ross K, Golub TR, Olefsky JM \& Lodish HF (2002) Profiling gene transcription in vivo reveals adipose tissue as an immediate target of tumor necrosis factoralpha: implications for insulin resistance. Diabetes 51, 3176-3188

Rui L, Yuan M, Frantz D, Shoelson S \& White MF (2002) SOCS-1 and SOCS-3 block insulin signaling by ubiquitinmediated degradation of IRS1 and IRS2. Journal of Biological Chemistry 277, 42394- 42398.

Saumon G, Martet G \& Loiseau P (1996) Glucose transport and equilibrium across alveolar-airway barrier of rat. American Journal of Physiology 270, L183-L190.

Senn JJ, Klover PJ, Nowak IA, Zimmers TA, Koniaris LG, Furlanetto RW \& Mooney RA (2003) Suppressor of cytokine signaling-3 (SOCS-3), a potential mediator of interleukin6-dependent insulin resistance in hepatocytes. Journal of Biological Chemistry 278, 13740-13746.

Sidossis LS, Mittendorfer B, Walser E \& Wolfe RR (1999) Regional disposal of intravenously infused glucose during prolonged hyperglycemia-hyperinsulinemia. Journal of Nutritional Biochemistry 10, 547-554.

Straczkowski M, Kowalska I, Nikolajuk A, Dzienis-Straczkowska S, Szelachowska M \& Kinalska I (2003) Plasma interleukin 8 concentrations in obese subjects with impaired glucose tolerance. Cardiovascular Diabetology 2, 5 .

Sugahara K, Freidenberg GR \& Mason RJ (1984) Insulin binding and effects on glucose and transepithelial transport by alveolar type II cells. American Journal of Physiology 247, C472C477.

Umpierrez GE, Isaacs SD, Bazargan H, You X, Thaler LM \& Kitabchi AE (2002) Hyperglycemia: an independent marker of in-hospital mortality in patients with undiagnosed diabetes. Journal of Clinical Endocrinology and Metabolism 87, 978-982.

Van den Berghe G (2004) How does blood glucose control with insulin save lives in intensive care? Journal of Clinical Investigation 114, 1187-1195.

Van den Berghe G, Wouters PJ, Bouillon R, Weekers F, Verwaest C, Schetz M, Vlasselaers D, Ferdinande P \& Lauwers P (2003) Outcome benefit of intensive insulin therapy in the critically ill: Insulin dose versus glycemic control. Critical Care Medicine 31, 359-366.

Van den Berghe G, Wouters P, Weekers F, Verwaest C, Bruyninckx F, Schetz M, Vlasselaers D, Ferdinande P, Lauwers P \& Bouillon R (2001) Intensive insulin therapy in the critically ill patient. New England Journal of Medicine 345, 1359-1367.

Vanhorebeek I, De Vos R, Mesotten D, Wouters PJ, De WolfPeeters C \& Van den Berghe G (2005) Protection of hepatocyte mitochondrial ultrastructure and function by strict blood glucose control with insulin in critically ill patients. Lancet 365, 53-59.

Vriesendorp TM, Morelis QJ, Devries JH, Legemate DA \& Hoekstra JB (2004) Early post-operative glucose levels are an independent risk factor for infection after peripheral vascular surgery. A retrospective study. European Journal of Vascular and Endovascular Surgery 28, 520-525. 
White RH, Frayn KN, Little RA, Threlfall CJ, Stoner HB \& Irving MH (1987) Hormonal and metabolic responses to glucose infusion in sepsis studied by the hyperglycemic glucose clamp technique. Journal of Parenteral and Enteral Nutrition 11, 345-353.

Wood DM, Baines DL, Woollhead AM, Philips BJ \& Baker EH (2004a) Functional and molecular evidence for glucose transporters in human airway epithelium. American Journal of Respiratory and Critical Care Medicine 169, A672.
Wood DM, Brennan AL, Philips BJ \& Baker EH (2004b) Effect of hyperglycaemia on glucose concentration of airways secretions. Clinical Science 106, 527-533.

Yendarumi S, Fulda GJ \& Tinkoff GH (2003) Admission hyperglycemia as a prognostic indicator in trauma. Journal of Trauma 55, 33-38.

Yu W-K, Li W-Q, Li N \& Li J-S (2003) Influence of acute hyperglycaemia in human sepsis on inflammatory cytokine and counterregulatory hormone concentrations. World Journal of Gastroenterology 9, 1824-1827. 